\title{
EL DERECHO A LA AUTOCONSERVACIÓN EN LA EXISTENCIA EN LA FILOSOFÍA DEL DERECHO DE JOHANN G. FICHTE Y EN LA ÉTICA DE HERMANN COHEN
}

\author{
Héctor Oscar Arrese Igor \\ Universidad Nacional de La Plata (República Argentina) \\ harreseigor@gmail.com
}

\begin{abstract}
Resumen
En este trabajo buscamos explorar relaciones conceptuales relevantes entre la idea de un derecho de los ciudadanos a la existencia en la ética de H. Cohen, y la teoría del derecho de Johann G. Fichte, en relación con la hipótesis de M. Heidegger y H. G. Gadamer acerca de una influencia fichteana sobre el neokantismo de Marburg.
\end{abstract}

Palabras ClaVE: derecho, existencia, estado, ciudadanía, filosofía alemana.

\section{Abstract}

In this paper we intend to explore relevant conceptual relationships between the idea of a citizen's right to existence in H. Cohen's ethics and J. G. Fichte's theory of right, in connection with M. Heidegger's and H.-G. Gadamer's hypothesis of the Fichtean influence on Marburg's Neo-Kantianism.

KEYWORDS: right, existence, state, citizenship, German philosophy.

\footnotetext{
D1 Como apunta Köhnke, ya en los primeros tiempos del neokantismo, la filosofía de Kant fue interpretada a través de Fichte, por ejemplo, en la obra de Kuno Fischer (Köhnke 1986, 186 ss.). El idealismo fichteano impulsó la recepción de Kant en la Alemania de la segunda mitad del siglo XIX, dominada por el materialismo, el psicologismo y el cientificismo matemático-natural, luego de la pérdida de vigencia de la dialéctica hegeliana. La razón de la seducción que ejerció Fichte fue su defensa de la libertad absoluta del yo frente al determinismo de la causalidad mecánica natural. A partir de Fichte, se intentó fundamentar la autonomía moral del yo, entendido como una razón volente.
} 
Los festejos del 19 de mayo de 1868, dados en su honor, atestiguan el entusiasmo general que provocó el llamado del retorno a Fichte en unión con Kant ${ }^{1}$. De allí que en aquellos tiempos se denominara al pensamiento de Helmholtz, Haym, Fortlage y Fischer como una "filosofía kantiano-fichteana" (Kantisch-Fichtesche Philosophie). (Köhnke 1986, p. 193).

La tesis de la presencia de elementos fichteanos en el neokantismo ha sido introducida por Heidegger (1919) y luego retomada por Hans-Georg Gadamer (1975), quien ha afirmado que "el neokantismo había sido más bien un retorno a Fichte" 2 .

Siguiendo esta sugerencia, Heinz (1997) ha hecho un aporte valioso respecto de la influencia de Fichte en la escuela del sudoeste alemán. Pero no se dispone aún de ningún estudio de conjunto sobre la presencia de la filosofía fichteana en la Escuela de Marburg, si bien algunos investigadores han señalado elementos en común.

En este sentido, es importante el aporte de Solowiejczyk (1930), quien ha destacado algunos puntos de contacto entre la filosofía fichteana y la Logik der reinen Erkenntnis de Cohen, tales como la eliminación de la cosa en sí, la unificación de la materia y la forma, con el consiguiente rechazo de lo a posteriori y de la intuición sensible, así como la deducción legal de todo el conocimiento a partir de un principio supremo (el yo de Fichte y el pensamiento puro de Cohen), y la concepción funcional de este principio supremo (Solowiejczyk 1930, p. 51n.).

Pero es poco lo que se ha logrado en la búsqueda de indicios de una influencia clara de la filosofía fichteana, en particular del Grundlage des Naturrechts (en adelante, GNR), sobre la Ethik des reines Willens (en adelante, $E r W$ ) de Cohen, si bien son de destacar los aportes de Schmid (1993) y Stolzenberg (2002). Schmid ha señalado acertadamente el carácter social que tiene la subjetividad en el GNR y la $E r W$. Para decirlo con sus propias palabras:

“[...] Cohen toma una posición fichteana. Él rechaza por cierto la concepción gnoseológica de la Teoría de la Ciencia de Fichte, pero sin embargo concede que Fichte ha realizado consideraciones absolutamente valiosas desde el punto de vista práctico: descubre al yo como un yo social, que solo puede constituirse en comunidad con un tú. Estas reflexiones se encuentran ante todo en el 'Fundamento del derecho natural de acuerdo con los principios de la teoría de la ciencia' de 1796 que, junto con el 'Fundamento de la totalidad de la teoría de la

1 Acerca del trasfondo político de los festejos en honor a Fichte, sobre todo en relación con la necesidad de unificar a Alemania bajo el imperio prusiano, cfr. Köhnke 1986, pp. 188 ss.

2 "Der Neukantianismus war viel eher eine Rückwendung zu Fichte gewesen (Gadamer, 1975, 88). Antes de Gadamer, Heidegger ya había afirmado que el neokantismo es más bien un neo-fichteísmo (Heidegger 1919, pp. 142 ss.). 
ciencia' de 1794, persigue el objetivo de aclarar la libre autodeterminación y de la libertad" 3 .

Pero Schmid no ha avanzado más allá de su sugerencia. Por otro lado, Stolzenberg ha estudiado la influencia de Fichte sobre Cohen en lo atinente al rol constitutivo de la alteridad para la deducción de la autoconciencia (Stolzenberg 2002, pp. 428-432). Sin embargo, Stolzenberg no ha entrado en el análisis de conceptos comunes a ambas teorías, tales como la relación legal, el Estado o el derecho de los ciudadanos a la autoconservación. De este modo, existe un verdadero hueco en el debate en torno a las relaciones entre Cohen y Fichte.

A pesar de la falta de estudios exhaustivos sobre las relaciones entre la filosofía de Cohen y la de Fichte, considero que pueden mostrarse conexiones conceptuales relevantes entre las tesis principales del GNR y la $\mathrm{Er} W$.

En efecto, las teorías de Cohen y Fichte presentan a primera vista semejanzas importantes, en particular, en la fundamentación de sus respectivos conceptos de autoconciencia. Cohen demuestra la necesidad de la autoconciencia a partir de la estructura intersubjetiva de la alteridad, al igual que Fichte, quien considera que el yo nunca puede ser autoconsciente si no es reconocido por el otro como un ser racional. Es decir, que en ambos casos, la alteridad es constitutiva de la autoconciencia. No obstante, el concepto de autoconciencia es diferente en cada teoría, dado que en Fichte se trata de una relación que el sujeto individual establece consigo mismo, y en Cohen es el sujeto de la voluntad común de la persona jurídica del Estado.

También hay coincidencias significativas respecto de los dos conceptos de relación legal. Por un lado, en ambas teorías, el derecho es la condición de posibilidad de la autoconciencia. Cohen encuentra esta categoría en la base del Estado y, por lo tanto, de toda relación legal, lo que significa que el derecho es la mediación histórica de esta forma de subjetividad. Fichte tampoco puede pensar la constitución de la autoconciencia del yo si su libertad no está protegida por la comunidad legal que establece con el otro, en torno al principio del derecho. Pero también existe otra coincidencia significativa entre ambas teorías de la relación legal. La razón de esto es que tienen una estructura dialógica, dado que no pueden concebir al yo como aislado del otro.

A pesar de estas semejanzas, hay una diferencia de peso entre el $G N R$ y la $E r W$, que reside en sus respectivas ideas del Estado. En Cohen, el Estado es ante todo una

3 "[Damit] nimmt Cohen eine fichtesche Position ein. Er verwirft zwar die erkenntnistheoretische Konzeption der Wissenschaftslehre Fichtes, gesteht diesem aber zu, dass er in praktischer Hinsicht durchaus bedenkenswerte Überlegungen angestellt habe. Dies etwa dort, wo er das Ich als soziales Ich entdeckt, als ein Ich, das sich nur in Gemeinschaft mit einem Du konstituieren kann. Diese Überlegungen finden sich vor allem in der 1796 erschienenen 'Grundlage des Naturrechts nach Prinzipien der Wissenschaftslehre' welche zusammen mit der 1794 erschienenen 'Grundlage der gesamten Wissenschaftslehre' das Ziel verfolgt, die freie Selbstbestimmung und damit das Problem der Freiheit zu klären" (Schmid 1993, pp. 60-61). 
democracia de tipo deliberativo, cuyo corazón mismo es la actividad parlamentaria. Fichte, por el contrario, considera indispensable la unificación de los tres poderes en manos del ejecutivo, por razones de eficiencia en la aplicación de la ley. Solo queda en el GNR un espacio para el ejercicio de la soberanía popular en el caso en que el gobierno deba ser sometido a juicio político a instancias del eforato, único órgano contralor de la actividad estatal.

Pero existe aún otro concepto común a ambas, que permite acercar de algún modo las dos ideas del Estado. Ambas otorgan una importancia decisiva al derecho de cada ciudadano a mantenerse en la existencia, esto es, a la autoconservación. El derecho inalienable a la existencia tiene su fundamento, tanto en la $\mathrm{ErW}$ como en el GNR, en sus respectivas teorías de la autoconciencia. Cohen sostiene que la autoconciencia, en tanto que sujeto de la voluntad estatal, puede expresarse por medio de la legislación si todos los ciudadanos pueden participar de este proceso, lo que conlleva el respeto por las condiciones materiales de su existencia biológica. Lo mismo ocurre en la teoría fichteana, donde la autoconciencia de cada sujeto se realiza por medio de su cuerpo articulado, cuyo móvil principal es la satisfacción de sus necesidades vitales.

El tema de la autoconservación en Cohen ha sido estudiado en trabajos importantes, tales como el de Wiedebach (1997), quien lo ha puesto en relación con el principio de la conservación de la energía. También Winter (1980) constituye un estudio interesante sobre la autonomía como autoconservación, entendida como una forma de realización del ciudadano como un individuo.

El problema de la autoconservación o del derecho a la existencia en Fichte ha merecido la atención del estudio de Rickert, (1922/1923), como un elemento esencial del socialismo fichteano. Batscha (1970) y luego Merle (1997) han hecho aportes importantes a la investigación de este tema en conexión con la teoría de la propiedad y la división del trabajo. En la misma línea pueden mencionarse también los trabajos más recientes de Hahn (2003), De Pascale (1988) y Hell (2003).

Pero no se ha publicado ningún estudio acerca de las similitudes y diferencias entre las dos ideas de autoconservación. Se trata de un punto central de ambas teorías, cuyo análisis puede arrojar luz sobre el debate acerca de la influencia de la filosofía política de Fichte sobre la ética social de Cohen. Este trabajo intenta hacer un aporte a la investigación sobre este problema, en orden a una mejor interpretación de la $\operatorname{Er} W$, una obra clave del neokantismo de Marburg.

\section{La autoconservación como condición del derecho}

\section{1. La realización de la autoconciencia en el Estado}

Cohen piensa al Estado como una comunidad legal, estructurada como una persona jurídica. El Estado consiste en la expresión continua de la voluntad pura, es decir, la voluntad común expresada en la Constitución, que consiste en una serie de reglas que deben seguirse para promulgar y aplicar la ley. Se trata de condiciones tales 
como la exigencia del sufragio universal para elegir a los legisladores, la igualdad de voz y voto en el Parlamento, la ausencia de coacción sobre los representantes, su eventual inmunidad parlamentaria, etc. El Estado y el derecho tienen entonces una forma contractual, es decir, que resultan del acuerdo permanente de los ciudadanos entre sí $(E r W, 248)$.

Pero, además de tener esta forma, el Estado tiene un contenido. Se trata de una forma de subjetividad, realizada en su personalidad jurídica, que Cohen denomina como autoconciencia $(\mathrm{Er} W, 80)^{4}$. Es una subjetividad ficticia y puramente legal, sin fundamentos en ninguna comunidad prepolítica, tal como alguna comunidad de sangre, lengua o tradiciones. La persona jurídica aparece como opuesta a los intereses individuales de los ciudadanos, porque es producto del acuerdo de todos. Por lo tanto, representa los intereses universales de la comunidad política, y trasciende las voluntades individuales y empíricas de cada uno de sus miembros.

\section{2. La autonomía como autoconservación}

Una vez que Cohen ha concluido que la autoconciencia es la tarea de la voluntad pura en el Estado, quedan por establecer las reglas que pautan las condiciones que debe cumplir la legislación y la aplicación de la ley, para realizar la autoconciencia en el Estado. La actividad de la legislación presupone el ejercicio de ciertos derechos. Los ciudadanos, en tanto que legisladores, fundan todos sus derechos en el derecho a la libertad. Ésta se realiza bajo la forma de la autonomía en sus cuatro aspectos: la autolegislación, la autodeterminación, la autorresponsabilidad y la autoconservación. Las reglas que debe seguir la legislación para realizar la autoconciencia consisten en la puesta en práctica de la autonomía en todos sus aspectos.

La autonomía es entonces en primer lugar la capacidad de autolegislación, de elaborar la ley que luego uno mismo se comprometerá a cumplir en el futuro $(\mathrm{Er} W$, pp. 326 ss.). Esta es la condición fundamental para el establecimiento de la correlación entre el individuo y la universalidad de la ley, que es característica de la autoconciencia. Pero la legislación es una actividad que exige la autodeterminación de los ciudadanos y sus representantes. Este es el segundo significado de la autonomía, que prohíbe el ejercicio de la coacción, ya sea en la forma de extorsión o amenazas de todo tipo, o del uso directo de la fuerza física contra la persona de los legisladores que deliberan y deciden promulgar cada ley particular. La autonomía como autodeterminación significa que el sujeto efectivamente elabora la ley a partir de sus propias decisiones ( $E r W$, pp. 345 ss.). Pero si permanecemos en esta dimensión de la autonomía, dejaremos aún sin resolver otra cuestión capital.

Se trata del problema de la imputación legal, sin la cual no puede aplicarse la ley. Un ciudadano es imputable si tiene conocimiento de las circunstancias de la

4 Acerca del Estado como concepto modelo de la autoconciencia, cfr. Schmid, 1993, pp. 69-70; Winter 1980, p. 349; Görland 1912, p. 240. 
acción que ha llevado a cabo, pero, sobre todo, si puede reconocerse a sí mismo como el autor de un atentado contra la ley. Se trata de la tercera dimensión de la autonomía, que Cohen denomina como la autorresponsabilidad ( $E r W$, pp. 357 ss.). La autonomía en este sentido es posible solo si aquel que debe someterse a la ley puede identificarse a sí mismo como el legislador que la ha promulgado. De este modo, Cohen va introduciendo los diversos niveles de la autonomía, desde la capacidad formal de autolegislarse, pasando por la capacidad efectiva de llevar a cabo esta acción, hasta llegar a la identificación de sí mismo como el origen de la ley.

Pero, a pesar de que el sujeto autorresponsable tiene un sentido de la identidad personal y es capaz de identificarse con las leyes y cumplirlas, o de asumir sus transgresiones, no es todavía un individuo de carne y hueso. Dicho de otro modo, para que el sujeto pueda actuar a partir de sus propias decisiones y, por lo tanto, hacerse cargo de ellas, debe cuidar de su existencia biológica. Es decir, que el sujeto puede realizar su autonomía solo en la medida en que a la vez satisfaga necesidades vitales, tales como el hambre y la sed. De allí deriva Cohen la exigencia de la autoconservación. Sin embargo, su argumentación es más compleja, porque está íntimamente entrelazada con los resultados obtenidos en su investigación sobre la autorresponsabilidad. Veamos cómo procede Cohen en su demostración de la dimensión moral de la corporalidad.

Cohen trata la cuestión de la autonomía como autoconservación a partir de la respuesta a una objeción que puede surgir frente al concepto de autorresponsabilidad. Este argumento parte del análisis del proceso de individualización, que permite que el delincuente, una vez que ha sido juzgado y condenado, se atribuya a sí mismo el crimen y finalmente decida resocializarse. La objeción plantea que este proceso de individualización estaría en contradicción con la universalidad de la autoconciencia, a la que debe servir la autorresponsabilidad. Es decir, dado que la autorresponsabilidad debe descansar en el conocimiento de sí mismo y exige la reflexión del criminal sobre los motivos de su acción, llevaría al abandono de la perspectiva de la intersubjetividad, e implicaría una recaída en la perspectiva individualista, que Cohen intenta superar en su teoría del derecho estatal ( $E r W$, p. 373).

Sin embargo, a pesar de que la sentencia del juez no puede suplantar a la autorreflexión del individuo, tiene un aspecto objetivo e insoslayable desde el punto de vista legal, que es el de la condena y la determinación de la pena. La necesidad de establecer un castigo para el criminal es una refutación clara del intelectualismo, porque supone que el crimen es algo más que un mero error del pensamiento. Si el crimen fuera el resultado de un mero error cognitivo, sería suficiente entonces con una compensación por los daños y perjuicios objetivos que resultaron de la acción delictiva. Por el contrario, la ley prevé una serie de normas que apuntan a la transformación y modelación del carácter y de la constelación de valores que orientan la acción del sujeto.

Es decir, la sentencia supone una relación lógica entre el concepto del crimen y el de la pena, porque ambos están tipificados y definidos en el Código Penal. Toda vez que el derecho solo puede ser comprendido bajo la forma del contrato, debe contener necesariamente también el momento de la reparación o del resarcimiento, para 
la eventualidad de que uno de los contrayentes no haya cumplido con las normas contraídas. Con otras palabras,

"Su culpa legal es su culpabilidad, que él no solo debe sentir, sino también reparar. El juicio del juez sobre el hecho objetivo de un crimen es, de acuerdo con esto, al mismo tiempo un juicio sobre el criminal, gracias a la necesidad lógica de la restricción deducida. Y este juicio sobre el criminal se convierte, en virtud de la necesidad lógica, en un juicio sobre su culpabilidad; este es su pena" 5 .

La determinación de la pena es el resultado de la aplicación de la ley por el juez. Pero la ley es la expresión de la voluntad pura y de la autoconciencia. Por lo tanto, el concepto de la pena pone en relación íntima al sujeto individual de la acción con la comunidad de los colegisladores. Es decir, que el concepto de la pena hace posible la relación objetiva que existe entre la autorresponsabilidad del individuo y la universalidad de la autoconciencia.

Esta conclusión arroja luz sobre otro error, que consiste en separar la pena de la culpa en el sentido moral, y rechazar a esta última del ámbito del derecho. Esta es la concepción de la responsabilidad propia de quienes piensan al derecho como una mera técnica y lo desvinculan de la ética. Contra la reducción de la responsabilidad al cumplimiento exterior de la pena, Cohen exige que el criminal restaure su relación con la comunidad legal, a fin de que pueda volver a ser un colegislador en el Estado.

Sin embargo, esto es posible solo una vez que haya cumplido con la pena objetiva que se le ha fijado.

"La pena lo eleva sobre la culpa. La culpa le da solo el medio de liberación de la penitencia. Pero está la pregunta de si la penitencia en sentido moral puede liberarlo de la culpa. Probablemente su arrepentimiento se vuelva tan amargo que él permanezca fijado a la autoacusación, la compunción, la desesperación. Debemos dejar aquí fuera de consideración otros pensamientos, tales como los de la religión, que podrían proporcionar un complemento a la penitencia, porque se trata solo de la autoconciencia en base a la autolegislación y sus desarrollos" ${ }^{6}$.

5 "Seine juristische Schuld ist seine Schuldigkeit, die er nicht allein zu fühlen, sondern einzurichten hat. Das Urteil des Richters über den Tatbestand eines Verbrechers ist demnach kraft logischer Notwendigkeit in der gezogenen Einschränkung zugleich ein Urteil über den Verbrecher. Und dieses Urteil über den Verbrecher wird daher kraft logischer Notwendigkeit zu einem Urteil über seine Schuldigkeit; diese ist seine Strafe" (ErW, p. 374).

6 "Die Strafe hebt ihn dann sogleich über die Schuld hinaus. Die Schuld gibt ihm nur das Befreiungsmittel der Busse. Aber es ist die Frage, ob die Busse im ethischen Sinne ihn von der Schuld zu befreien vermag. Vielleicht wird seine Reue so bitter, dass er in der Selbstanklage, in der Zerknirschung, in der Verzweiflung hängen bleibt. Andere Gedanken, etwa die der Religion, die ihm eine Ergänzung der Busse verschaffen möchten, müssen hier ausser Betracht bleiben, wo es sich nur um das Selbstbewusstsein auf dem Grunde der Selbstgesetzgebung und ihrer Entwickelungen handelt". (ErW, p. 377). 
Como sostiene Cohen en este fragmento, el concepto de pena, como determinación objetiva de la compensación que el criminal debe pagar por el daño producido, consuma la liberación de la ética respecto de la religión, porque supera el concepto de la penitencia como la expiación por los pecados y la idea consiguiente de purificación moral.

Hay quienes afirman que el criminal, una vez sentenciado, dejaría de ser un ciudadano, y se convertiría de nuevo en un colegislador solo una vez cumplida su pena. Pero esta afirmación es incorrecta, porque, en la medida en que el criminal acepta sobre sí la pena y la cumple, se encuentra en continuidad con su actividad previa de legislación y promulgación de la ley. Este es el sentido de las siguientes palabras de Cohen:

"Cuando luego de la expiación puede lograrse la restitución de un hombre íntegro, allí debe dominar el presupuesto de que este resultado no aparece luego de la expiación conseguida, sino que ya se establece durante la expiación y con la toma de posesión de la pena" 7 .

La legislación solo tiene sentido si el autor de la ley es el mismo sujeto que luego se somete a ella, lo que implica el cumplimiento de las sanciones que ha consentido de antemano para los casos de desviación de la ley. En el caso del delito de hurto, la compensación que debe garantizar la pena puede ser determinada de muchas maneras. Sin embargo, el asesinato presenta el problema insalvable de que no hay compensación posible para quien ha perdido la vida por culpa del criminal.

Para resolver este problema, Cohen debe en primer lugar considerar la legitimidad de la pena de muerte como compensación proporcional al delito de homicidio. En este caso, parecería razonable la sanción con la pena de muerte, porque quien ha destruido intencionalmente a otro ciudadano, no puede pensarse de ninguna manera como un posible cooperador y colegislador en el Estado. Por lo tanto, no tendría ningún sentido la aplicación de una pena con el objetivo de devolver al criminal al ejercicio pleno de la ciudadanía. Sin embargo, la gravedad de la pena de muerte exigiría que el juez pueda emitir un juicio exhaustivo e infalible acerca de las intenciones del criminal. Pero solo el criminal puede saber si efectivamente ha querido matar o no, porque solo él tiene acceso a su conciencia moral.

Por lo tanto, la aplicación de la pena capital significaría en la práctica la extralimitación de las atribuciones del juez. Dada la imposibilidad de dictaminar concluyentemente sobre la culpa del delincuente, implicaría también la instauración del derecho de la venganza o de la compensación simétrica de un asesinato con otro. La

"Wenn nun aber nach der Abbüssung die Restitution zu einem integern Menschen erfolgen kann, so muss dabei die Voraussetzung obwalten, dass diese Wirkung nicht erst nach erfolgter Abbüssung eintritt, sondern während der Abbüssung und mit dem Antritt der Strafe bereits einsetzt". (ErW, p. 378). 
única alternativa que quedaría para poder aplicar la pena correspondiente a este delito, sin violar la autorresponsabilidad del criminal, es dejar en sus manos la decisión de suicidarse en el caso de que considere que tuvo la intención firme y clara de cometer el homicidio. Pero puede verse claramente lo absurdo de una tal pena, y por lo tanto su inaplicabilidad (ErW, p. 380).

Cohen esgrime aún un argumento adicional para rechazar la pena de muerte, que surge de la fundamentación misma de su teoría. El Estado consiste en la realización de la tarea de la autoconciencia, lo que no es posible si todas las voluntades individuales de los ciudadanos no participan en la constitución de la voluntad común de la ley. Se trata entonces de la tarea de la legislación, que nunca debe darse por concluida, porque constituye la esencia misma del Estado como persona jurídica. Es una tarea infinita, porque siempre está abierta al futuro. Pero, si la pena de muerte se aplicara sobre cualquier ciudadano, entonces su voluntad particular dejaría de participar en la tarea de la autoconciencia, lo que contradice el concepto mismo del Estado.

Por otro lado, en la medida en que la tarea es infinita, nunca se puede dar a un ciudadano por perdido o etiquetarlo como un ciudadano ejemplar, ya que la ciudadanía es una tarea que se construye día a día. Es decir, que

"La tarea no puede nunca lograr su solución adecuada; pero tampoco puede ser arrancada del corazón de un hombre. De allí se sigue que, como ningún hombre es bueno, tampoco ningún hombre es malo"8.

Por lo tanto, debe renunciarse a pronunciar cualquier tipo de juicio moral definitivo sobre los ciudadanos, lo que deja sin fundamento la aplicación de la pena de muerte.

La autonomía como autorresponsabilidad no puede realizarse sin el cuidado por la autoconservación, porque, si el ciudadano muere, desaparecen con ello todas las condiciones para la realización de la autoconciencia. De allí que Cohen afirme de modo concluyente:

"La autoconservación tiene como supuesto indeleble ante todo al individuo natural [...]. Con el alma del ser humano no puede comenzarse legalmente nada, ni conseguir nada, cuando ella es el alma del hombre asesinado. El alma puede tener un sentido ético, desde el punto de vista legal, solo como el alma de un hombre vivo" $"$.

8 "Die Aufgabe kann niemals zur adäquaten Lösung kommen; aber sie kann auch niemals aus dem Herzen eines Menschen herausgerissen werden. Daraus folgt, dass, wie kein Mensch gut ist, auch kein Mensch böse ist". (ErW, p. 381).

$9 \quad$ "Die Selbsterhaltung hat aber, wie das Selbst überhaupt, das natürliche Individuum zur unauslöschlichen Voraussetzung. Mit der Seele des Menschen ist rechtlich nichts anzufangen, und nichts auszurichten, wenn sie die des getöteten Menschen ist. Die Seele kann 
La objeción religiosa a favor de la pena de muerte, que sostiene que la existencia más allá de la muerte permite al individuo continuar con su progreso moral, no tiene sustento alguno en la teoría de Cohen, porque la ética no puede realizarse fuera del Estado. Por lo tanto, la autoconservación es la forma fundamental de la autonomía, porque es la condición sine qua non del progreso moral. Pero, dado que la ética es una forma más de la conciencia cultural, y la cultura es el producto de la acción humana, la autoconservación es en realidad la condición y el supuesto básico de la cultura humana. Por eso Cohen afirma,

"la autoconservación, este es el A y el O. El aseguramiento de la cultura, es decir, la elevación de la cultura, tiene como supuesto imprescindible a la autoconservación realizada sin excepciones" ${ }^{10}$.

Cohen concluye que la existencia de los ciudadanos debe ser preservada celosamente por el Estado democrático de derecho, para garantizar su universalidad moral. De este modo, Cohen da respuesta a lo que considera como el problema fundamental de la ética, esto es, la correlación entre el individuo y la universalidad. Esta es posible solo cuando cada ciudadano, sin excepciones, puede participar en la elaboración de la ley. Si cada ciudadano es el autor de la ley, entonces la ley se aplicará del mismo modo para todos. Si la universalidad de la ley se realiza en la autoconciencia del Estado, el otro término de la relación, es decir, el individuo, necesariamente existirá, dado que se garantizan las condiciones del ejercicio de la autonomía. Es decir, que el individuo puede relacionarse con la universalidad cuando su existencia corporal es un asunto de Estado.

\section{El derecho a la existencia}

La discusión sobre el problema de la autoconservación en Fichte es mucho más articulada que la de Cohen, y tiene sus raíces en su simpatía por la Revolución Francesa, en particular, por las ideas políticas de Robespierre. La exigencia de Fichte de garantizar a todos los ciudadanos la subsistencia (das Lebenkönnen) es muy similar a los planteos de Robespierre, quien, en su discurso del 2 de diciembre de 1792, afirmó que todos los miembros de la sociedad deben tener asegurado el acceso a los frutos de la tierra que son necesarios para su existencia. Este es el sentido de su famosa alocución:

einen ethischen Sinn rechtlich nur haben, als die Seele des lebendigen Menschen". (ErW, p. 382).

10 "Selbsterhaltung, das ist das A und das O. Die Sicherung der Kultur, das ist die Erhöhung der Kultur, sie hat zur unerlässlichen Voraussetzung die ausnahmslos durchgeführte Selbsterhaltung" (ErW, p.387). 
“¿Cuál es el primer fin de la sociedad? Mantener los derechos imprescriptibles del hombre. ¿Cuál es el primero de esos derechos? El de existir. La primera ley social es, pues, la que asegura a todos los miembros de la sociedad los medios para existir, todas las demás se subordinan a éstas: la propiedad no ha sido instituida, ni ha sido garantizada, sino para cimentar aquella ley, es por lo pronto para vivir que se tiene propiedades, y no es verdad que la propiedad pueda jamás estar en oposición con la subsistencia de los hombres" $"$.

Este es el sentido del artículo 21 de la Constitución Jacobina de 1793 (Braun 1991, p. 28). Fichte consideraba que todas las instituciones sociales debían cooperar con este fin. Pero ni la nobleza ni la iglesia aportaban nada a la garantía del derecho a la existencia del pueblo. Por eso, Fichte proponía dar por anulados los contratos que el Estado tenía con estas instituciones.

Del derecho a la autoconservación de los ciudadanos se deriva la teoría fichteana de las fronteras naturales, que consiste en que el Estado tiene derecho a la cantidad de terreno y recursos naturales que necesita para satisfacer las necesidades de los ciudadanos. Por lo tanto, en caso de necesidad, se puede avanzar sobre el territorio de los demás Estados, ya sea por la fuerza militar o por medios económico-financieros (Batscha 1970, p. 192).

Fichte pensaba que este derecho fundamental podía ser garantizado solo en una economía planificada centralmente, porque no confiaba en la economía de libre mercado, que consideraba que dejaba a la subsistencia del pueblo librada al azar de que haya gente que quiera ofrecer o buscar tal trabajo o tales mercancías $(S W, \mathrm{X}, 554)$. El liberalismo podría lograr en el mejor de los casos un mero equilibrio ciego del comercio, liberado de toda reglamentación estatal $(S W, \mathrm{X}, 511)$.

\section{1. La deducción del derecho de propiedad a partir del concepto de autoconciencia}

Fichte construye todo el edificio de su teoría del derecho y el Estado a partir de la demostración de la existencia del yo como autoconciencia, porque el mundo jurídico es la condición de posibilidad de la subjetividad. Se trata de una argumentación compleja, que intentaré reconstruir en lo que sigue, para comprender el rol que juega el derecho a la existencia en el GNR.

11 "Quel est le premier objet de la société? c'est de maintenir les droits imprescriptibles de l'homme. Quel est le premier de ces droits? celui d'exister. La première loi sociale est donc celle qui garantit à tous les membres de la société les moyens d'exister; toutes les autres sont subordonnées à celle-là; la propriété n'a été instituée ou garantie que pour la cimenter; c'est pour vivre d'abord que l'on a des propriétés. Il n'est pas vrai que la propriété puisse jamais être en opposition avec la subsistance des hommes." Esta cita ha sido tomada del website: http://membres.lycos.fr/discours/discours.htm. Cfr. Buhr 1991, pp. $43-44$. 
El yo se constituye como tal cuando puede acceder a la autoconciencia, es decir, en el momento en que puede atribuirse a sí mismo la acción de conocer un objeto en el mundo sensible, y está en condiciones de saber que es un ser racional. Esto es posible solo si otro yo lo exhorta a la acción, es decir, si lo reconoce como un ser racional. Pero esta relación de reconocimiento exige que el otro se abstenga de aplicar la fuerza o la coacción sobre el yo para que actúe de un modo determinado, porque la exhortación a la libertad requiere que el yo pueda responder a ella como le parezca mejor.

Por otro lado, si el yo se comporta racionalmente frente a la invitación del otro, entonces el otro podrá confirmarlo plenamente como un igual. Pero el otro podrá saber que el yo se comporta racionalmente solo si el yo respeta su esfera de libertad y no lo obliga a seguir un determinado curso de acción. Dicho de otro modo, el yo podrá ser reconocido plenamente por el otro como un ser racional en la medida en que él mismo reconozca al otro como tal. Por lo tanto, la relación de reconocimiento que hace posible la autoconciencia del yo debe ser necesariamente una relación de reconocimiento recíproco.

La condición fundamental de esta relación de reconocimiento mutuo es el principio del derecho, que prescribe a los yoes el respeto por la libertad de acción del otro. El principio del derecho, según el $\S 4$, garantiza a cada persona la misma esfera de acción que aquella de la que gozan todas las demás (GNR, § 4; SW, III, p. 52; AA, I, 3, 358 ). Esto significa que cada persona tiene el mismo derecho que las demás a realizar sus fines en el mundo sensible.

Pero, la persona puede llevar a cabo el fin que se haya propuesto, solo si el mundo sensible está estructurado del mismo modo tanto cuando esta persona lo conoció al elaborar el concepto del fin de la acción, como cuando lleva a cabo el fin propuesto efectivamente en el mundo sensible. La única perturbación imprevisible del mundo sensible puede provenir de la causalidad libre de otra persona, porque este tipo de causalidad no está sujeta a leyes mecánicas. Por lo tanto, debe neutralizarse esta posible perturbación del mundo sensible por medio de la coacción de la otra persona, esto es, de la determinación de su voluntad según reglas.

Los individuos deciden formar parte de un Estado solo para proteger su libertad y su propiedad de los posibles ataques de los demás. Fichte parte del supuesto del egoísmo universal, del que se desprende la necesidad de que los ciudadanos deleguen todo su poder en un tercero, encargado de dirimir las disputas de derechos. Se trata de los gobernantes, que deben unificar el poder ejecutivo, legislativo y judicial en sus manos, por razones de eficiencia en la aplicación del principio del derecho.

Dado que el derecho de propiedad se ejerce sobre esferas de acción, en realidad está orientado a la garantía de la realización de fines que sean compatibles con los fines de otras personas ${ }^{12}$. Se trata de la regulación de las metas de acción que se

12 Cfr. Rickert 1922/1923, p. 161. En este sentido, es posible encontrar una analogía con el concepto kantiano de propiedad privada, que solo adquiere legitimidad si es compatible con la libertad (y, por tanto, la propiedad) de todos. 
propone cada uno, porque la propiedad de cada uno es en realidad la parte del mundo sensible que nos permite usos posibles de cosas materiales.

A su vez, el cuerpo es la mediación indispensable para que las autoconciencias se conviertan en individuos y puedan actuar en el mundo sensible. La corporalidad es el equivalente a la cantidad de libertad de la que dispone cada persona. Esto significa que el cuerpo es el conjunto de las esferas de acción que resulta de la aplicación del principio del derecho. La totalidad de los cuerpos es entonces la comunidad legal misma.

Fichte sostiene que el cuerpo articulado supone la autoconciencia de la persona, porque es el resultado de la atribución a sí misma de una esfera de acciones posibles. Dicho de otro modo, el cuerpo es parte integrante de la autoconciencia. Esto significa que el cuerpo tiene una estructura reflexiva, porque es parte integrante de la vuelta del yo sobre sí mismo. Sin embargo, esto no significa que en Fichte el cuerpo se repliegue a la esfera de lo privado, porque esto significaría caer en el solipsismo. Por el contrario, es una condición básica de la regulación de la existencia en común.

II. 2. La deducción del derecho a la existencia a partir del concepto del cuerpo humano como un producto natural organizado

Fichte considera que el derecho fundamental, que el Estado debe garantizar, es el derecho a conservar la propia existencia. Pero esta finalidad debe hallarse en la constitución del cuerpo humano mismo, toda vez que siempre y en todo caso la acción en el mundo sensible es posible gracias a la atribución a sí mismo de un cuerpo articulado.

El problema a considerar es, entonces, de qué modo está prevista, en el funcionamiento del cuerpo humano, esta tendencia inevitable de la persona a permanecer existiendo en el futuro. Si se pudiera constatar que el cuerpo tiene una tendencia a la autoconservación, entonces puede decirse que el cuerpo de todo sujeto, sea o no una persona, dispone de mecanismos que permiten determinar la voluntad en orden a querer su propia autoconservación.

Fichte fundamenta sus conclusiones en los resultados de su investigación en el parágrafo 5 acerca del cuerpo humano articulado. Allí concluye que el cuerpo articulado es un producto natural organizado, esto es, una totalidad orgánica. La naturaleza puede ser pensada solo teleológicamente, como teniendo una finalidad que determina a su vez los fines de cada una de sus partes. Si el cuerpo tiene la función de realizar acciones libres en el mundo sensible, entonces debe tener algún mecanismo inmanente que le permita realizar este fin.

Se trata de un mecanismo inherente al cuerpo y que permite dar cuenta de su deseo de autoconservación. Se trata del dolor que le produce al cuerpo la falta de nutrición y de hidratación, es decir, el hambre y la sed. Estos mecanismos fisiológicos provocan tal dolor en el cuerpo, que la voluntad se determina siempre y en todo momento a calmarlo. 
De este modo, la naturaleza, como totalidad organizada teleológicamente, permite explicar la necesidad del cuerpo de autoconservarse. Este es el móvil (Triebfeder) básico y fundamental de toda actividad del cuerpo y, toda vez que el cuerpo es la condición de posibilidad de la actividad libre sobre el mundo sensible, la autoconservación es el último móvil y objetivo de la acción de toda persona.

Por esta razón, el Estado debe garantizar la nutrición e hidratación de todos sus ciudadanos si pretende asegurar su libertad. Este es el sentido de estas afirmaciones de Fichte:

"Por lo tanto, el objetivo último y universal de toda actividad libre es el poder vivir. Todos se proponen esta meta; $y$, en la medida en que es garantizada la libertad en general, este objetivo es garantizado. Sin el logro [de esta meta] la libertad y la continuidad de la persona no serían posibles en absoluto" ${ }^{13}$.

De aquí se desprende que el derecho constitutivo y fundamental de la ciudadanía es el derecho a la existencia ${ }^{14}$. Fichte plantea, por un lado, que la autoconservación (el poder-vivir, la subsistencia) es el fin supremo de toda actividad humana, mientras que, cuando define el derecho original (Urrecht), entiende a la actividad libre como último fin. Pero, ¿cómo podemos ser libres, si nuestro fin supremo es la obediencia al determinismo de la naturaleza (la satisfacción del hambre y la sed)? ¿No es la autoconservación más bien el supuesto de todo fin, antes que el fin supremo mismo? (Merle 2001, pp. 167-168).

La relación entre la libertad y la naturaleza debe entenderse aquí más bien en sentido teleológico, ya que en la teoría de Fichte, el logro de la autoconservación es el primer paso en la liberación del determinismo de la naturaleza, de la necesidad y la dependencia (Merle 2000, pp. 127-128; 2001, p. 169). El ordenamiento legal apunta meramente a la conservación material de los hombres, y no se ocupa de su perfeccionamiento moral y espiritual (objeto de la teoría moral) (Merle 2001, p. 169).

13 "Der höchste und allgemeine Zweck aller freien Thätigkeit ist sonach der, leben zu können. Diesen Zweck hat jeder; und wie daher die Freiheit überhaupt garantirt wird, wird er garantirt. Ohne seine Erreichung würde die Freiheit, und die Fortdauer der Person, gar nicht möglich seyn" (GNR, § 18; SW, III, 212; AA, I, 4, 22).

14 Fichte complementa en otros textos el ideal del mero Lebenkönnen con el más ambicioso de una angenehmes Leben. Fichte toma este ideal del pietismo, esto es, una vida en la cual el hombre no sea tratado como un animal de carga (Lasttier), sino que pueda llevar una vida decente de acuerdo a su función social (ej., un campesino puede darse por satisfecho con una alimentación vegetariana y puede ir a trabajar con zapatos de madera y usar en los días festivos zapatos de cuero, mientras que el sabio necesita de una alimentación variada y de una reine Umgebung). Cada uno debe poder trabajar con alegría y poder ver el cielo en condiciones de tranquilidad (Der geschlossene Handelstaat, SW, III, 414 ss.). Cfr. el ejemplo de los Herrenhuter (Excurse zur Staatslehre, SW, VII, 609). (Cfr. Hell 2003, 137; Merle 1997, 204). 
En el contrato de propiedad, cada ciudadano se compromete a no impedir al otro la realización de los fines que se propone en el mundo sensible. El derecho a la existencia determina entonces claramente el significado del contrato de propiedad. El cuerpo es la totalidad de la esfera de acciones posibles del otro, por lo tanto, su protección implica el respeto por la libertad del otro.

Este es el sentido del principio que debe contener toda constitución que aplique el derecho natural, y dice: "cada uno debe poder vivir de su trabajo" (Jederman soll von seiner Arbeit leben können). (GNR, § 18; SW, III, 212; AA, I, 4, 22).

Por eso, la unidad de distribución de la propiedad es la profesión u oficio que cada ciudadano desee desempeñar. Esta constituye el contenido concreto de la esfera de acción de cada ciudadano y, dado que el último fin de cada acción es satisfacer las necesidades de nutrición del agente, la profesión u oficio del ciudadano debe permitirle vivir de ella. La tarea más propia y original del Estado, en virtud del contrato de ciudadanía, es la regulación de las instituciones de modo tal, que sea posible que cada uno viva de su trabajo, como veremos más adelante ${ }^{15}$.

El ejemplo que pone el mismo Fichte aclara el sentido de este principio: en un pueblo de ciudadanos que anden desnudos no tiene sentido desarrollar el oficio de sastre, porque un sastre no podría vivir allí de su trabajo (GNR, § 18; SW, III, 213; AA, I, 4, 23). Si el Estado reconoce la pretensión del ciudadano de realizar tal o cual oficio, esto es, si reconoce su propiedad declarada, entonces debe garantizar las condiciones para su realización. Volviendo al ejemplo del sastre, si los ciudadanos reconocen su derecho a ejercer este oficio, deben comprometerse a comprarle sus trajes. Respetar la propiedad del individuo significa reproducir las condiciones que hacen posible esa propiedad.

\section{Consideraciones finales}

De lo argumentado hasta aquí puede concluirse que tanto Cohen como Fichte fundamentan la actividad del Estado en el respeto del derecho a la existencia de sus ciudadanos, o sea, a la satisfacción de sus necesidades básicas. Ambas teorías coinciden en que la corporalidad de los ciudadanos es la condición de posibilidad del sistema legal, si bien se fundan en razones diferentes.

15 Por eso puede decirse que en Fichte no hay ciudadanos "abstractos", sino siempre "concretos", dado que se definen de acuerdo con su rol y lugar en la división racionalizada del trabajo. De este modo, el ciudadano logra su individualidad y particularidad en la medida en que participa en la lucha de su comunidad contra la naturaleza por medio del trabajo. El estatus social del individuo caracteriza su definición como ciudadano (Batscha 1981, pp. 276-277). 
En la $E r W$, la autoconciencia no es una realidad espiritual suprasensible que de algún modo misterioso se desarrolle dentro de nuestra conciencia individual, sino que es un producto cultural, es decir, que es el resultado de la acción del hombre en la historia. La autoconciencia es la acción misma del Estado, y es realizada efectivamente gracias a la actividad de la legislación. Pero estas afirmaciones son muy abstractas y no dejan en claro cómo es posible que la autoconciencia se realice progresiva y continuamente en la historia, si no se garantiza la existencia corporal de cada ciudadano, porque son sus acciones quienes mantienen viva a la voluntad pura del Estado. De allí la necesidad de introducir el requisito de la autoconservación en la teoría de Cohen. Solo si el Estado garantiza a los ciudadanos la autoconservación en la existencia corporal, puede garantizar a su vez su autoconservación como comunidad legal.

Este es uno de los motivos fundamentales del rechazo enérgico a la pena de muerte en la $E r W$. Si el criminal presumiblemente ha aceptado la ley que él mismo ha promulgado, argumenta Cohen, entonces el cumplimiento de la pena por su transgresión es parte fundamental de aquel consentimiento previo. Pero luego el criminal necesariamente debe recorrer el proceso de resocialización necesario para retomar la actividad de la realización de la autoconciencia, que es una parte insustituible de la ciudadanía. Por eso, la pena de muerte significa no solo la aniquilación del individuo particular, sino que también atenta contra la comunidad espiritual del Estado.

Si bien Cohen no tiene una teoría acerca de los mecanismos por medio de los cuales el Estado debe garantizar la subsistencia de todos y cada uno de los ciudadanos, esta es una exigencia irrenunciable de todo Estado justo, como se sigue de lo que se ha argumentado hasta aquí. Pero no solo es coherente con esta teoría la idea de una planificación de la distribución de ingresos y recursos, centralizada en el Estado, sino que también es plausible la mediación de estos recursos por medio de un sistema de cooperativas, organizado estatalmente, aun cuando Cohen no haya elaborado una teoría completa en este sentido (Günther 1971, pp. 195-196).

El objeto que tienen las cooperativas en la teoría de Cohen es devolver al ciudadano el señorío de sí mismo, que le ha quitado sistemáticamente el modo de producción capitalista ${ }^{16}$. La industrialización ha llevado al obrero a un estado tal, que se ha convertido en un mero medio para incrementar la riqueza del capitalista, cuando no del Estado mismo. El remedio para esta situación inmoral es otorgar al ciudadano la participación en la dirección del proceso de producción, como un colegislador de la empresa, junto con sus compañeros (van der Linden 1994, pp. 158-159; Lübbe 1963, p. 244).

16 Cfr. Giesecke 1990, p. 122. No podemos dejar de advertir aquí una línea de interpretación del trabajo asalariado similar a la "esclavitud a tiempo parcial" de Marx, y con la idea del alieni iuris que Kant toma del viejo derecho romano para referirse a quienes no tienen otra cosa que ofrecer que su propia persona y, por eso mismo, se convierten en sujetos de derecho ajeno. 
Solo de este modo, el obrero será tratado como un fin en sí mismo -en el sentido kantiano que Cohen le otorga a esta consigna- y no ya como un instrumento para los fines de otros. Pero el obrero no recuperará el dominio sobre sus acciones si sigue dependiendo del capricho de los capitalistas para poder satisfacer sus necesidades básicas. Por eso, la participación en la cooperativa constituirá un cambio significativo en las relaciones de producción capitalistas, solo si a la vez se garantiza la subsistencia de quienes participan en ella ${ }^{17}$.

Al igual que en la $E r W$, Fichte fundamenta el derecho de los ciudadanos a la existencia en el carácter indispensable de su corporalidad para la realización del derecho. El cuerpo articulado es el conjunto de acciones posibles de que dispone cada individuo. Dado que el derecho regula las esferas de acción de cada uno de los ciudadanos, para que todos tengan disponible el mismo conjunto de oportunidades, el derecho tiene su lugar de aplicación en el cuerpo mismo de cada ciudadano.

Por lo tanto, el ciudadano del Estado fichteano puede dar por anulado el contrato de ciudadanía, si su derecho a existir no ha sido garantizado. Pero el derecho a existir tiene como correlato la obligación de trabajar. Es decir, que si el ciudadano no trabaja, el Estado considerará que ha incumplido con su contrato de ciudadanía y dará lugar a las sanciones que correspondan.

El Estado es la mediación indispensable para la vigencia de este derecho, porque el mercado es demasiado azaroso y arbitrario para hacerlo. Por eso, Fichte desarrolla, digámoslo así, un diseño institucional interesante que haría posible el desarrollo de un conjunto de oportunidades iguales para todos. Y en este punto, la teoría fichteana es mucho más explícita que el neokantismo de Cohen.

Fichte retomó entonces la herencia de la Revolución Francesa, y en especial de Robespierre, y elaboró una teoría del derecho donde el hombre concreto e individual tiene un lugar central. Cohen se hizo eco de esta idea para fundamentar su socialismo ético y explicar el modo en que la autoconciencia se hace realidad en la historia humana. Tanto Cohen como Fichte se enfrentaron con el problema de la desigualdad e injusticia que produce el mercado cuando es dejado de la mano del Estado. Se trata de propuestas interesantes, válidas para un lugar y momento históricos determinados, pero con consecuencias legítimas más allá del contexto en el que nacieron. Lo argumentado hasta aquí nos permite evaluar el alcance -y las limitaciones- de autores reputados como "idealistas", aunque en teoría moral y política no olvidaron que una teoría normativa debe ser construida teniendo en cuenta también las condiciones sociales de la existencia que hacen posible la autonomía, en el caso de Cohen, o la acción libre, en el caso de Fichte.

17 El concepto de una democracia empresarial ha influido en algunos teóricos contemporáneos. Cfr. van der Linden1998, pp. 229-230. 
Referencias bibliográficas

Abreviaturas utilizadas

AA: Johann Gottlieb Fichte: Gesamtausgabe der Bayerischen Akademie der Wissenschaften. Hrsg. v. Reinhard Lauth u. Hans Jacob. Stuttgart-Bad Cannstatt 1962ff. (se cita como "AA“, con indicación del volumen y de la paginación). El Grundlage des Naturrechts nach Principien der Wissenschaftslehre se encuentra en I. Abteilung (Werke), 3. Band. Werke 1794-1796. Hrsg. von Reinhard Lauth und Hans Jacob unter Mitwirkung von Richard Schottky. 1966.

ErW: Cohen, H., Ethik des reinen Willens, en: (2002), Herman Cohen. Werke, herausgegeben vom Hermann-Cohen-Archiv am Philosophischen Seminar der Universität Zürich unter der Leitung von Helmut Holzhey, Band 7, System der Philosophie. 1. Teil. Ethik des reinen Willens, Georg Olms Verlag, Hildesheim-Zürich-New York. Einleitung von Peter A. Schmid. Nachdruck der 2. revidierten Auflage, (Berlin, Bruno Cassirer 1907).

GNR: Fichte, J.G., Grundlage des Naturrechts nach den Prinzipien der Wissenschaftslehre.

SW: Johann Gottlieb Fichte: Sämtliche Werke. Hrsg. v. Immanuel Hermann Fichte. Leipzig 1845f. (se cita como "SW“, con indicación del volumen y de la paginación).

Bibliografía secundaria

Batscha, Z. (1970), Gesellschaft und Staat in der politischen Philosophie Fichtes. Frankfurt am Main, Europäische Verlagsanstalt.

(1981), Studien zur politischen Theorie des deutschen Frühliberalismus. Frankfurt am Main, Suhrkamp Verlag.

Braun, J. (1991), Freiheit, Gleichheit, Eigentum. Grundfragen des Rechts im Lichte der Philosophie J.G. Fichtes. Tübingen, J.C.B. Mohr (Paul Siebeck).

Buhr, M. (1991), "Die Philosophie Johann Gottlieb Fichtes und die Französische Revolution", en Buhr, Manfred, Losurdo, Domenico (Hsrg.), (1991), Fichte - die Französische Revolution und das Ideal vom ewigen Frieden. Mit Unterstützung des Istituto Italiano per gli Studi Filosofici, Napoli, Berlin, Akademie Verlag, pp. 9-73.

De Pascale, C. (1988), "Droit à la Vie, Nature et Travail chez J.G. Fichte". Archives de Philosophie. 51: 597-612.

Gadamer, H. G. (1975), "Subjektivität und Intersubjektivität, Subjekt und Person”, en Hans Georg Gadamer: Gesammelte Werke, Bd. 10: Hermeneutik im Rückblick, Tübingen, J.C.B. Mohr (Paul Siebeck), 1995.

Giesecke, P. (1990), Kant und der Sozialismus. Studien zum Marburger Neukantianismus, Philosophisches Kritizismus und Kritischen Rationalismus. München, Dissertation. 
Görland, A. (1912), "Hermann Cohens systematische Arbeit im Dienste des kritischen Idealismus". Kant-Studien, XVII: 222-251.

Günther, H. (1971), System und Fortschritt im Denken Hermann Cohens. Köln, Dissertation.

Hahn, K. (2003), "Die Relevanz der Eigentumstheorie Fichtes im Zeitalter der Globalisierung unter Berücksichtigung Proudhons und Hegels". Fichte-Studien, Band 24, pp. 155-163.

Heinz, M. (1997), "Die Fichte-Rezeption in der südwestdeutschen Schule des Neukantianismus". Fichte-Studien, Band 13, pp. 109-130.

Heidegger, M. (1919), Phänomenologie und transzendentale Wertphilosophie. Vorlesung Sommersemester 1919, en Gesamtausgabe Bd. 55/56, Frankfurt a. M., Vittorio Klostermann, pp. 119-203, 1987.

Hell, J., (2003) "Stellung und Spuren einer Sozialethik in Fichtes Philosophie". Fichte-Studien, Band 24, Amsterdam-Atlanta, Rodopi, pp. 135-141.

Köhnke, K. Ch. (1986), Entstehung und Aufstieg des Neukantianismus. Die deutsche Unversitätsphilosophie zwischen Idealismus und Positivismus. Frankfurt am Main, Suhrkamp.

Lübbe, H. (1963), "Neukantianische Sozialismus". Politische Philosophie in Deutschland. Studien zu ihrer Geschichte, Basel, Schwabe Verlag, pp. 85125, en Ollig, H.L., (Hrsg.), Materialen zur Neukantianismus Diskussion, Darmstadt, Wissenschaftliche Buchgesellschaft, pp. 219-263, 1987.

Merle, J.-Ch. (1997), Justice et progrès. Paris, Presses Universitaires de France.

(2000), "Le droit de proprieté chez Fichte", en Bienenstock, M., CrampeCasnabet, M., Dans quelle mesure la philosophie est pratique. Fichte, Hegel. Avec la collaboration de Jean-Francois Goubet. Fontenay/Saint-Cloud, Ens Éditions, pp. 159-172, 2000.

(2001), "Eigentumsrecht (§§ 18-19)", en Merle, J.-Ch., (Hrsg.), Johann Gottlieb Fichte. Grundlage des Naturrechts. Klassiker Auslegen, Band 24, Akademie Verlag, Berlin, pp. 159-172.

Rickert, H. (1922/1923), "Die philosophischen Grundlagen von Fichtes Sozialismus". Logos. Zeitschrift für systematische Philosophie, Heft 11, pp. 149-180.

Solowiejczyk, J. (1930), Das reine Denken und die Seinskonstituierung bei Hermann Cohen. Berlin, Dissertation.

Stolzenberg, J. (2002), "Fichte im Neukantianismus. Probleme der Fichte-Rezeption bei Wilhelm Windelband, Heinrich Rickert, Hermann Cohen und Paul Natorp", en Alexy, R., Meyer, L. Paulson, S., Sprenger, G., (Hrsg.), Neukantianismus und Rechtsphilosophie. Mit einer Einleitung von Stanley Paulson. BadenBaden, Nomos Verlagsgesellschaft, pp. 421-434, 2002.

Van der Linden, H. (1994), "Cohens sozialistische Rekonstruktion der Ethik Kants", en Holzhey, H., (Hrsg.), Ethischer Sozialismus. Frankfurt, Suhrkamp, pp.146165. 
(1998), “A Kantian Defense of Enterprise Democracy”, en Kneller, J., Axinn, S., (eds.), , Autonomy and Community. Readings in Contemporary Kantian Social Philosophy, New York, State University of New York Press, pp. 213-237, 1998.

Wiedebach, H. (1997), Die Bedeutung der Nationalität für Hermann Cohen. Hildesheim-Zürich-New York, Georg Olms Verlag.

Winter, E. (1980), Ethik und Rechtswissenschaft. Eine historisch-systematische Untersuchung zur Ethik-Konzeption des Marburger Neukantismus im Werke Hermann Cohens, Berlin, Duncker \& Humblot. 